\title{
Determinants of Smart Energy Demand Management: An Exploratory Analysis
}

\author{
Zaheer Tariq $^{1}$, Sergio Cavalieri ${ }^{2}$, and Roberto Pinto ${ }^{2}$ \\ ${ }^{1}$ University of Bergamo, \\ Department of Management, Economics and Quantitative Methods, Bergamo, Italy \\ zaheer.tariq@unibg.it \\ ${ }^{2}$ University of Bergamo, Department of Engineering \\ CELS - Research Group on Industrial Engineering, Logistics and Service Operations \\ \{sergio.cavalieri, roberto.pinto\}@unibg.it
}

\begin{abstract}
The unprecedented rise of population with increasing energy consumption has necessitated the stabilization of dwindling energy resources to secure the provision of energy. Electricity production and distribution through smart grids is a key component in delivering reliable, efficient, and low-carbon energy for a sustainable development of the society, and to meet the growing demands of electricity. Smart electricity grid is a complex system of systems that requires sophisticated collaboration tools and intelligent techniques with active participation from all its connected users. A dynamic role and a proactive participation of consumers and societies with the integration of distributed energy resources are highly anticipated for the long-term sustenance of these grids. This paper discusses and identifies key determinants of the demand side sustainable collaboration in a smart way (resulting as what we address as smart energy demand) through the involvement of pro-active consumers.
\end{abstract}

Keywords: Smart demand, collaboration, sustainability, intelligent systems, sustainable consumption patterns, energy demand management.

\section{Introduction}

Cultural, social, and economic factors are increasingly modifying the consumption patterns, shifting the consumers' behaviors from a mere individual attitude to satisfy personal needs to a more collaborative process, resulting in a sustainable value creation. Thanks to a growing impetus in promoting sustainable consumption patterns, individuals are more conscious of their role in their communities, and are aware that their direct and collective participation can affect the current and future life of their society. Conversely, many sustainability strategies and corporate social responsibility (CSR) practices mainly address environmental aspects [1], neglecting the impact of global over-consumption [2], and overlooking the role of the consumer and the societal involvement.

In our understanding, a holistic approach is required to effectively deal with the current challenges posed by the sustainable development principles: consumers (and 
their communities at large) should be explicitly encouraged to be directly engaged through a more participative and collaborative behavior, factually realizing a collaborative consumption strategy, that is a technology-enabled sharing of goods and services between consumers that requires enhanced forms of collaborations [2-4].

Dealing with sustainability challenges finds its roots in a shift of mindset towards the achievement of more efficient consumption patterns. The support provided by properly designed collaboration platforms would increase the possibilities for producers and consumers to establish a mutual collaboration, seeking an equilibrium between supply and demand both in time (e.g. finding a customer when products are available, finding suppliers when demand upsurges) and space (e.g. finding a supplier close to a customer, or vice versa). Moreover, these common platforms can support pro-active consumers in acting interchangeably as users or providers of goods or services in their relation with other consumers according to the specific contexts and needs (i.e. privates that sells extra energy produced via photovoltaic panels installed on the house's roof).

As a result, changing the consumption patterns, moving towards a collaborative and sustainable process involving different participants, with distinct requirements and interests, requires a completely new approach to demand management. Under this premise, the nature itself of the demand changes, requiring a different connotation. Therefore, we refer to such a demand with the term Smart Demand, that is a demand signal coming from a collaborative process (see Section 2 for a detailed description).

The purpose of this paper is to provide a ground definition of smart demand, illustrating its main components. Along this, it analyzes the importance of active demand side participation in the case of energy demand management as result of the uprising role of smart electricity grid systems. Further, the paper highlights the key challenges under different dimensions. Attaining the benefits of smart grid technologies requires increased collaborative efforts between utilities and its connected customers. The smart grid concept supports the functioning of such energy systems with the integration of proactive consumers that contribute to the energy generation through their own systems, and share the excess with other consumers and utility grids.

The paper is structured as follows. Section 2 discusses the Smart Demand concept and the main components. Section 3 illustrates the smart demand applied in the energy sector, under the smart grids concept. Finally, Section 4 reports the conclusions, emphasizing some key challenges to be addressed by leveraging the smart demand concept.

\section{Defining Smart Demand}

The demand resulting from a collaborative consumption process differs substantially from the traditional forms of demand as usually conceived. For our purpose, we deem the term Smart Demand as a simple yet comprehensive term expressing the main characteristics of the demand signal expressed in a collaboration environment. In this environment, the individual demand can be shifted in time and/or compensated through other participatory efforts of the community. The "smartness" of the demand 
depends upon the smartness of the actions undertaken to reduce/shift/redistribute its profile under the collaborative systems by considering the mutual gains. We envision three main dimensions along which we characterize a smart demand:

Sustainability: Traditionally, much of the attention has been given to promote the sustainability design for production related impacts. Extensive efforts are also being made towards promoting those technologies and designs that can play an important role for moderating the overall consumption level and its related impacts [5]. However, a systematic and holistic approach to address a social nature of consumption (such as promoting collaborative consumption) is still lacking in the user-centered and behavioral related design efforts. In view of this, there is a growing interest in accommodating the social-technical dimension towards consumption by applying social practices in the technical-design process [6]. To get the detailed insights, about users and their behaviors under user-centered approaches, different research methods and the ways of approaching users are being adopted from multi-disciplinary fields. With the efforts, based on cognitive and environmental psychology, behavior-based approaches include applying the persuasive designs, intelligent technologies, and design scripts [6].

Collaboration: Collaborative consumption is not limited to the communal use of products and services, but the primary objective is to promote and encourage active role of consumers towards sustainable communities. These communities collaborate to foster a sustainable development in different sectors such as infrastructure, mobility, energy, waste and food [7]. By adopting such consumption patterns, people get the ownership benefits with less personal burden, cost savings, and lower impact on environment, hence showing more captivating alternative to standard and traditional buying and ownership styles. Consumers, as well as their communities, need to be empowered with adequate collaborative platforms to play their dynamic role for such transformation. For such platforms, three primary systems are created that are redistribution markets, collaborative lifestyles, and product service systems [4]. To achieve vast cultural and commercial implications, a trust and user experience plays a vital part in the platform of collaborative consumption [3]. This participation yields benefits not only related to the environment; it also generates social (improved quality standards, improved health conditions, employment generation) and economic benefits (such as new products/service innovations, more choices to customers and financial incentives).

Intelligence: The literature proposes different terms regarding intelligent products that are often associated with the smart products, smart objects and can be used interchangeably [8]. Further, concept realization of smart products also varies according to the number of terms used to describe or relate to them [9]. Accordingly, in this paper, smart products and intelligent products are used as interchangeable. McFarlane et al. [10] defined intelligent products as the products that are able to represent their physical (locations) along information based (conditions) characteristics. Smart products can be defined as the products having the following characteristics [8-10]: (i) have its distinctive identity; (ii) sensing and storage ability towards measurement of systems; (iii) ability to identify and sense other relevant attributes of external entities; (iv) can have an interconnection and communication power with other smart objects; (v) have 
decision power (i.e. make the decisions about themselves and external objects). Smart and intelligent products play a central role towards enabling a platform for system integration through a collaborative sustainable process. Smart products and services can assist consumers in using the collaborative platforms and can help them to analyze their consumption and demand patterns [11].

By this vision, Smart Demand is a sustainable collaborative demand sensed through embedded product/system intelligence, under the network of information and communication technology. Such a demand, with the help of information technology network and smart/intelligent objects, provides the sensing ability to observe the collaborative demand shifts/variations.

By highlighting the importance of consumers, and their pro-active participation in a community, we emphasize the fact that individuals' demand are smartly connected (through intelligent products and systems) towards a collaborative demand which may provide substantial benefits for a sustainable development.

\section{Smart Demand for Energy Demand Management}

Electricity production through Smart Grids is a key component in delivering an efficient and low-carbon energy for the sustainable economic infrastructure [12-13]. Smart Grids can be defined as a cost effective electricity delivery infrastructure, enhanced with information and communication facilities (including technologies that facilitate the efficient integration of renewable energy sources) to enable more efficient, reliable and secured grid operations with an improved customer service and a cleaner environment [12,14-15].

Energy sustainability has a key influence in the domain of sustainable developments. It requires a shift from traditional energy sources towards renewable energy ones. A smart grid vision facilitates the development of sophisticated collaboration tools and intelligent techniques for increased member participations and for incorporating the decentralized and fluctuating energy sources. It can assist in reducing the excessive burden on the grid by creating a balance between supply and demand [15]. This balance can be established through an effective demand side management (DSM) and proactive participants' efforts. DSM, an essential part of smart grids, is a cost effective tariff program for managing the electricity load that generates benefits both for utilities and consumers. Normally, under these programs consumers play a passive role because most decisions and actions are taken by utilities whilst consumers have little or no control. In addition, utility grids support the functioning of such energy systems with the integration of proactive consumers (also termed as prosumers) that contribute to the energy generation through their own systems, and share the excess with other consumers and utility grids. The proactive energy participants transform their passive role into the active role in the electricity generation and share the responsibility of reducing and optimizing the energy consumptions.

To achieve the true capability of a bidirectional flow of energy and information between utility grids and users, consumers along with their communities need to be encouraged for their involvement. It is estimated that their contribution (through 
demand response and renewable sources) will constitute from one-third to one-half of total smart grids benefits for sustainable energy [16].

Efficiency in energy sustainability refers to a curtailment in energy consumption without following the reduction in energy supply [17]. As referred above, adopting the social nature of consumption that is from a product-based approach to a practiceoriented approach (for collaborative systems) can also considerably strengthen this energy consumption.

Seeking energy sustainability in a broader societal perspective with the support of proactive consumers requires consumption modification along socially connected efforts. These community efforts enforce sustainable practices leading to sustainable behaviors. Consumers should actively participate to achieve the sustainability targets (with mutual gains consisting of economic, social and environmental benefits) through collaboration (creating the demand flexibility) with the help of intelligence (as intelligent products and systems).

Smart demand for energy demand management is envisioned as based on a tripod of sustainability, collaboration and intelligence (as shown in Fig. 1). An increased level of collaboration through highly intelligent tools and techniques reflects improved efforts toward a sustainable development. A prosumer-to-prosumer collaboration through collective decision-making (against divergent interests and perspectives) may seek energy autonomy / self-sufficiency in sustainable energy communities [7].

The more consumers enter into the dynamic prosumers' domain, the more significant impact they can have on the smart grid infrastructure. In views of Vogt et al. [18] a grid becomes smart when all endpoints contribute to its operations. Where endpoints should not be restricted only to generators but must also include power users (consumers along prosumers). A smart demand can ensure that the amount of energy generated is equal to the amount of energy demanded.

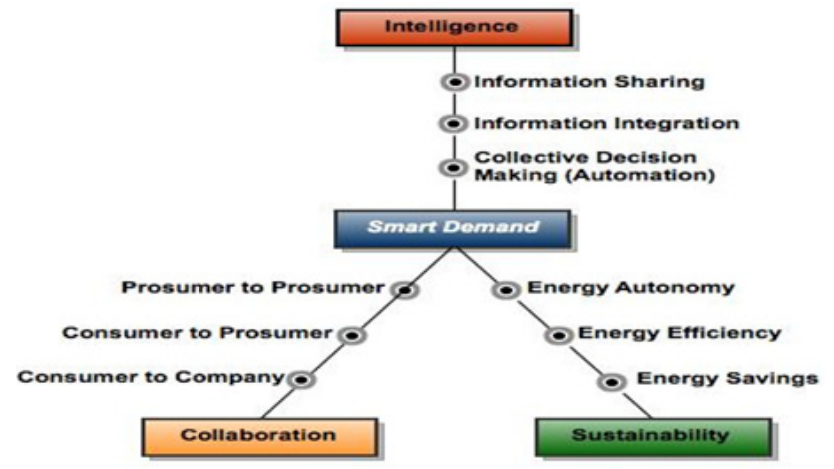

Fig. 1. Smart demand for energy demand management (Source: Authors)

Along with the tripod vision, collaborative arrangements in the energy context are strongly intertwined with the expected level of sustainability and the form of intelligence required. Such integrated consideration is highlighted in Table 1.

However, thorough implementation of smart demand management into a specific system model requires its comprehensive analysis in terms of tangible and intangible 
determinants (such as behavioral, motivational and cognitive aspects in consumer collaboration towards energy sharing). Such contextual determinants can generate mutual gains in the societal coordinative efforts towards achieving the sustainability.

Whereas most work related in this perspective overlooks the comprehensive analysis and hence partially comments these dimensions in collective way as a peak load saving strategies. Such as [19-20] focus only on the collaboration as a collective energy purchasing by overlooking the consumers proactive participation and other determinants such as behavioral factors in creating the demand flexibility under energy sharing perspective.

Table 1. Energy demand management through smart demand

\begin{tabular}{|c|c|}
\hline $\begin{array}{l}\text { Collaborative } \\
\text { arrangements }\end{array}$ & Integrated considerations \\
\hline $\begin{array}{c}\text { Consumer to } \\
\text { company }\end{array}$ & $\begin{array}{l}\text { Consumers collaborate through their energy demand information } \\
\text { sharing with the utilities to avoid consumption during peak hours, } \\
\text { being beneficial for customer (as savings) and for utility (as low } \\
\text { production costs). Both foster the sustainability as energy savings } \\
\text { conservations. }\end{array}$ \\
\hline $\begin{array}{c}\text { Consumer to } \\
\text { prosumer }\end{array}$ & $\begin{array}{l}\text { Collaboration that seeks energy efficiency (i.e. efficient usage of } \\
\text { energy and / or opting alternative supply sources). For such DSM, } \\
\text { participants integrate the network information (e.g. supply con- } \\
\text { straints) into their decision making towards consumption alterations. }\end{array}$ \\
\hline $\begin{array}{c}\text { Prosumer to pro- } \\
\text { sumer }\end{array}$ & $\begin{array}{l}\text { Collaboration for DSM by involving and promoting the role of pro- } \\
\text { sumers in the network towards incremental capacity of the supply } \\
\text { side leading to energy autonomy. It requires intelligent automation } \\
\text { systems that enable fully autonomous decision-making against di- } \\
\text { verse self-interests. }\end{array}$ \\
\hline
\end{tabular}

\section{Concluding Remarks and Future Challenges}

Leveraging on the smart grids concept, we posit that a pro-active participation of consumers through a collaborative process may provide substantial benefits for the long-term sustenance of the electricity infrastructure. Transferability of this process can also be envisioned in other contexts, as for example for the transportation demand management, which requires strong collaborative arrangements towards managing the travel / traffic demand (as modification and/or redistribution).

However, this potential role is determined by various factors (briefly highlighted in Table 2), ranging from self-interest layers to exogenous conditions that can induce the coordinated efforts of the users towards energy demand management. Smart demand illustration as energy demand management emphasizes the relationship of consumers along societal efforts towards energy sustainability. Such a relationship is heavily dependent on the self-interested participants, which may have an impact on the smart demand. Considering this, the same table provides a guideline for our future research 
Table 2. Future challenges to smart demand

\begin{tabular}{|c|c|}
\hline Intervention & Challenges \\
\hline \multirow{3}{*}{ Sustainability } & $\begin{array}{l}\text { Consumers' limited knowledge regarding their energy usage patterns and } \\
\text { its sustainability impacts can limit consumers' proactivity level. }\end{array}$ \\
\hline & $\begin{array}{l}\text { Embedded social practices, lack of societal pressures, lack of self- } \\
\text { efficacy awareness level and existing satisfaction level do not allow them } \\
\text { to pursue a change in their demand patterns. }\end{array}$ \\
\hline & $\begin{array}{l}\text { Investment costs regarding renewable energy sources, storage devices } \\
\text { and system implementation costs. }\end{array}$ \\
\hline \multirow{4}{*}{ Collaboration } & $\begin{array}{l}\text { Non-availability of tools to evaluate demand flexibility against technical } \\
\text { and economic benefits and costs [21] }\end{array}$ \\
\hline & $\begin{array}{l}\text { Electricity market structures, legislative, administrative and regulatory } \\
\text { barriers that suppress consumer participatory efforts. }\end{array}$ \\
\hline & $\begin{array}{l}\text { Consumer response fatigues and required attention to individual products } \\
\text { / electrical appliances could also have adverse impacts. }\end{array}$ \\
\hline & $\begin{array}{l}\text { Collaboration among participants raises the information security and data } \\
\text { privacy concerns. Such unauthorized access of data can hinder successful } \\
\text { implementation of collaborative platforms. }\end{array}$ \\
\hline \multirow{3}{*}{$\begin{array}{l}\text { Intelligence } \\
\text { (products and } \\
\text { systems) }\end{array}$} & $\begin{array}{l}\text { Costly access and overload of information with its required processing } \\
\text { efforts can create hindrance for the participation. }\end{array}$ \\
\hline & $\begin{array}{l}\text { Lack of user-friendly technologies that can monitor real time usage and } \\
\text { supply patterns assisting consumers to create demand flexibility. }\end{array}$ \\
\hline & $\begin{array}{l}\text { Technology costs and their financing options (such as smart meters) and } \\
\text { without these consumer participation is not possible. }\end{array}$ \\
\hline
\end{tabular}

to investigate about the most efficient coordination mechanisms by considering the optimality among dimensions of smart demand.

This paper raises some important aspects along different requirements, being the antecedent for building up the smart energy demand management model. The designing of this model does not only depend on the technological factors but also on those intangible factors that are related to consumers energy consumption and generation activities under the energy sharing context, being enabled by smart grids. Collectively absorbing these requirements into the system modeling for the demand side management may help to design proactive consumers' efficient energy management decision support system. Such system development can augment the smart grids economic impact.

\section{References}

1. Berns, M., Townend, A., Khayat, Z., Balagopal, B., Reeves, M., Hopkins, M.S., Kruschwitz, N.: The business of sustainability: What it means to managers now. MIT Sloan Management Review 51(1), 20-26 (2009) 
2. Sheth, J.N., Sethia, N.K., Srinivas, S.: Mindful consumption: A customer-centric approach to sustainability. Journal of the Academy of Marketing Science 39(1), 21-39 (2011)

3. Porter, M.E., Kramer, M.R.: The big idea creating shared value. Harvard Business Review 1(1), 62-77 (2011)

4. Brokaw, L.: Collaborative consumption: Drivers, systems, implications. MIT Sloan Management Review 11 (2011)

5. Thorpe, A.: Design's role in sustainable consumption. Design Issues 26(2), 3-16 (2010)

6. Scott, K., Bakkera, C., Quist, J.: Designing change by living change. Design Studies 33(3), 279-297 (2012)

7. Rae, C., Bradley, F.: Energy autonomy in sustainable communities-a review of key issues. Renewable and Sustainable Energy Reviews 16(9), 6497-6506 (2012)

8. Meyer, G.G., Framling, K., Holmstrom, J.: Intelligent products: A survey. Computers in Industry 60(3), 137-148 (2009)

9. Lopez, T.S., Ranasinghe, D.C., Harrison, M., Mcfarlane, D.: Adding sense to the internet of things: An architecture framework for smart object systems. Personal and Ubiquitous Computing Journal 16(3), 291-308 (2012)

10. Mcfarlane, D., Sarma, S., Chirn, J.L., Wong, C.Y., Ashton, K.: Auto id systems and intelligent manufacturing control. Engineering Applications of Artificial Intelligence 16(4), 365-376 (2003)

11. Meyer, G.G., Yeh, Y.C., Tsai, M.S.: Smart devices for demand side power consumption management. AASRI Procedia 2, 216-222 (2012)

12. Samad, T., Kiliccote, S.: Smart grid technologies and applications for the industrial sector. Computers and Chemical Engineering 47, 76-84 (2012)

13. Gao, J., Xiao, J., Liu, J., Liang, W., Chen, C.L.P.: A survey of communication / networking in smart grids. Future Generation Computer Systems 28(2), 391-404 (2012)

14. Moslehi, K., Kumar, R.: A reliability perspective of the smart grid. IEEE Transactions on Smart Grid 1(1), 57-64 (2010)

15. Ramchurn, S.D., Vytelingum, P., Rogers, A., Jennings, N.R.: Agent-based homeostatic control for green energy in the smart grid. ACM Transactions on Intelligent Systems and Technology 2(4), 91-97 (2011)

16. Heffner, G.: Smart grid - smart customer policy needs. In: International Energy Agency, pp. 1-24. IEA Energy Efficiency and Environment Division, Washington, DC (2011),

http: / / www. iea.org/publications/freepublications /

publication/sg_cust_pol.pdf

17. Schweizer-Ries, P.: Energy sustainable communities: Environmental psychological investigations. Energy Policy 36(11), 4126-4135 (2008)

18. Vogt, H., Weiss, H., Spiess, P., Karduck, A.P.: Market-based prosumer participation in the smart grid. In: 4th IEEE International Conference on Digital Ecosystems and Technologies (DEST), pp. 592-597. IEEE, Dubai (2010)

19. Vinyals, M., Bistaffa, F., Farinelli, A., Rogers, A.: Coalitional energy purchasing in the smart grid. In: 2nd IEEE International Energy Conference and Exhibition (ENERGYCON), pp. 848-853. IEEE, Florence (2012)

20. Vasirani, M., Ossowski, S.: Smart consumer load balancing: State of the art and an empirical evaluation in the spanish electricity market. Artificial Intelligence Review 39(1), 81-95 (2013)

21. Bel, C.A., Ortega, M.A., Escriva, G.E., MaríN, A.G.: Technical and economical tools to assess customer demand response in the commercial sector. Energy Conversion and Management 50(10), 2605-2612 (2009) 